\title{
Studies on the Pinctada fucata BMP-2 Gene: Structural Similarity and Functional Conservation of Its Osteogenic Potential within the Animal Kingdom
}

\begin{abstract}
Akiko Takami, Hirotaka Kato, Ryousuke Takagi, and Tomoyuki Miyashita
Department of Genetic Engineering, Faculty of Biology-Oriented Science and Technology, Kinki University, Nishimitani 930, Kinokawa City, Wakayama 649-6493, Japan

Correspondence should be addressed to Tomoyuki Miyashita; miyasita@waka.kindai.ac.jp

Received 26 December 2012; Accepted 5 March 2013

Academic Editor: Greg Demas

Copyright (C) 2013 Akiko Takami et al. This is an open access article distributed under the Creative Commons Attribution License, which permits unrestricted use, distribution, and reproduction in any medium, provided the original work is properly cited.

Bone morphogenetic protein (BMP)-2 plays an important role in morphogenesis in both vertebrates and invertebrates. BMP-2 is one of the most powerful bioactive substances known to induce the osteogenic differentiation of mesenchymal cells. We examined the structural and functional conservation of Pinctada fucata BMP-2 in inducing osteogenesis in the murine mesenchymal stem cells, $\mathrm{C} 3 \mathrm{H} 10 \mathrm{~T} 1 / 2$. Exposure of C3H10T1/2 cells to the recombinant mature fragment of Pinctada fucata BMP-2 resulted in osteoblastic differentiation. The sequence, SVPKPCCVPTELSSL, within the C-terminal portion of Pinctada fucata BMP-2, is homologous to the knuckle epitope of human BMP-2. This synthetic polypeptide was able to induce differentiation of C3H10T1/2 along the osteoblastic lineage, as confirmed by an increase in alkaline phosphatase activity, and the accumulation of calcium, as determined by von Kossa staining. Furthermore, using immunohistochemical staining, we observed an increased expression of collagen type I, osteopontin, and osteocalcin, which are known markers of osteogenesis. These results show that BMP-2 is conserved, not only in terms of its homology at the amino acid sequence, but also in terms of driving the formation of hard tissues in vertebrates and invertebrates.
\end{abstract}

\section{Introduction}

The transforming growth factor-beta (TGF- $\beta$ ) supergene family plays various roles in the regulation of cell growth, cell specialization, and morphogenesis $[1,2]$. More than 40 genes have been identified in the mammalian TGF- $\beta$ family [3], including the bone morphogenetic proteins (BMPs). BMPs are well-known regulators of bone and cartilage formation in vertebrates.

The BMPs and their homologs are also involved in the regulation of morphogenesis in the shells of mollusks [4-7]. Hard tissue in invertebrates is equivalent to bone of vertebrates in terms of the organization of accumulated minerals. Although it is to be expected that BMP-2 or - 4 participates in the formation of hard tissues such as the shells of mollusks, direct proof has not been reported. Previously, to examine the role of BMP-2 in morphogenesis and hard tissues formation of Pinctada fucata, we cloned the Pinctada fucata BMP-2 (PfBMP-2) gene using DNA obtained by PCR-based genome amplification as the probe [8]. The PfBMP-2 gene was expressed strongly in the inner part of the mantle tissue, corresponding to the nacreous aragonite shell layer. This suggested that BMP-2 has a key role in the nacreous layer formation. Recently, indirect proof that PfBMP-2 participates in the hard tissue formation of $P$. fucata was reported [9]. In that report, it was observed that there is a delay in the speed of regeneration in the inner shell surface following the inhibition of calcineurin by an intramuscular injection of cyclosporine A. The morphological abnormality of the crystal surface was also observed, mainly in aragonite regions, as well as a decrease in $B M P-2$ expression, suggesting an important role for $B M P-2$ in the nacreous layer formation [9]. This result also indicated that PfBMP-2 functions via a calcineurin/NFAT4 pathway.

Although the mechanism of $B M P-2$ gene induction in invertebrates is not well understood, a large number of vertebrate studies have attempted to outline the process. Runx $2 /$ Cbfa-1 binds to the $5^{\prime}$ flanking region and activates the 
transcription of human BMP-2 [10]. The relationship between calcineurin and $B M P-2$ expression has been reported in vertebrates [11]. In that report, the authors showed that BMP2 transcription was suppressed by cyclosporine but stimulated by ionomycin treatment and was stimulated in cells transduced with an adenovirus carrying the activated form of NFAT4. These results suggested that NFAT4 induces BMP-2 transcription via calcineurin during chondrogenesis.

Concerning a common factor in a bone and mollusk shell formation, some reports suggest that a BMP-2-like diffusible osteoinductive factor exists in the nacreous layer of the pearl oyster although the substances have not yet been identified [12-15]. Although not conclusive, these results imply a common signal transduction pathway between vertebrate and invertebrate hard tissue formations [16]. One candidate is BMP-2 or a fragment of the protein. If this reported diffusible factor is BMP-2 or a fragment, BMP-2 could represent a universal common factor, not only in the morphogenesis, but also in hard tissue formation in vertebrates and invertebrates animal. If true, it is necessary to prove its existence in the nacreous layer and to measure its potential to induce osteogenic differentiation. It would also be necessary to show that BMP2 is functionally conserved across species. Among bone morphogenetic proteins and their homologs in invertebrates, the only factors that have been proven to be compatible with vertebrate are Drosophila Dpp and A60 [17].

In this paper, we examined the osteoinductive potential of $P f B M P-2$ on the differentiation of mesenchymal cells C3H10T1/2 in vitro. Using histological analyses, our findings show that a purified recombinant $10-\mathrm{kDa}$ mature fragment of $P f B M P-2$ can induce osteogenic differentiation in C3H10T1/2 cells. Furthermore, we identified the functional domain of PfBMP-2. The recombinant PfBMP-2 or the synthetic polypeptide of the functional domain has the potential to be applied to regenerative medicine to a defective human bone.

\section{Materials and Methods}

2.1. Dot Matrix Analysis. A Dot matrix analysis [18] was carried out using the site Dotlet (http://myhits.isb-sib.ch/cgibin/dotlet) with a sliding window 23 and blosum 62 .

2.2. Preparation of the Recombinant Mature Fragment of $P f B M P-2$. Expression and purification of the recombinant mature fragment of $P f B M P-2$ in E. coli were performed, as described in previously [19].

2.3. Synthetic Peptides Production. Synthetic peptides, PGSVPKPCCVPTELSSLSLL (corresponding to the amino acid sequence of $P f B M P-2$ that showed the highest homology with the knuckle epitope of human BMP-2) and KIPKASSVPTELSAISTLYL (corresponding to amino acids 73-92 of human BMP-2 and acting as a positive control for this study) were purchased from Operon Biotechnologies, Inc. (Tokyo, Japan) and were dissolved in pure water to a concentration of approximately $20 \mathrm{mg} / \mathrm{mL}$.

2.4. Cell Culture. C3H10T1/2 mesenchymal stem cells (clone 8) were purchased from Human Science Research Resources
Bank (Osaka, Japan). C3H10T1/2 cells were plated into a $40 \mathrm{~mm}$ culture dish (Nunc, Roskilde, Denmark) or a 48-well cell culture plate (Iwaki Glass, Tokyo, Japan) at a density of $1.4 \times 10^{4} /$ dish and $1.2 \times 10^{3} /$ well, respectively. C3H10T1/2 cells were maintained in Dulbecco's Modified Eagle's Medium (DMEM; Gibco BRL, Gaithersburg, MD) supplemented with $10 \%$ FBS (Gibco BRL) and $100 \mu \mathrm{g} / \mathrm{mL}$ streptomycin (Gibco$\mathrm{BRL})$ at $37^{\circ} \mathrm{C}$ in a $5 \% \mathrm{CO}_{2}$ humidified incubator. For experiments, cells were grown in the presence of PfBMP-2 or the synthetic peptides at the indicated concentrations and time periods as described for each figure, with regular changes of media and new compound supplementations at each media change.

2.5. Alkaline Phosphatase (ALP) Activity Assay. To assay the enzymatic activity of ALP, the culture medium was removed and cell layers were washed with phosphate buffered saline (PBS, pH 7.4). Cells were lysed in $200 \mu \mathrm{L}$ of lysis buffer $\left(0.1 \mathrm{M} \mathrm{NaHCO}-\mathrm{Na}_{2} \mathrm{CO}_{3}, 2 \mathrm{mM} \mathrm{MgCl} 2,0.1 \%\right.$ Triton X-100) and the lysate transferred to a microtube for centrifugation at $15,000 \mathrm{rpm}$ for $5 \mathrm{~min}$ at $4^{\circ} \mathrm{C}$. $100 \mu \mathrm{L}$ of supernatant was transferred to a new microtube. The reaction was started by adding p-nitrophenyl phosphate to the tube at a final concentration of $8 \mathrm{mM}$. The reaction was incubated for $30 \mathrm{~min}$ at $37^{\circ} \mathrm{C}$ and then stopped by the addition of $100 \mu \mathrm{L}$ of $1 \mathrm{M} \mathrm{NaOH}$. The absorbance was measured at $405 \mathrm{~nm}$. ALP activity was expressed as micromoles of p-nitrophenol (p-NP) produced per minute per milligram of protein. The protein content was determined using the Pierce BCA Protein Assay Kit (Pierce Chemical Company, Rockford, IL, USA).

2.6. Alkaline Phosphatase Staining. For ALP staining, the culture medium was removed, and the $\mathrm{C} 3 \mathrm{H} 10 \mathrm{~T} 1 / 2$ cells were washed twice with PBS before fixing with $4 \%$ paraformaldehyde in PBS for $1 \mathrm{~min}$ at room temperature. The cell layers

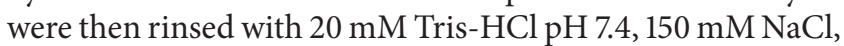
$0.05 \%$ tween 20. Staining was performed using an Alkaline Phosphatase Detection Kit (Chemicon, Temecula, CA, USA).

2.7. Von Kossa Silver Staining. For von Kossa staining, the culture medium was removed and the C3H10T1/2 cells were washed twice with PBS and fixed with $10 \%$ neutral formalin solution for $30 \mathrm{~min}$. The monolayers were then rinsed extensively with deionized water. The cells were treated with 5\% $\mathrm{AgNO}_{3}$ solution under ultraviolet light for $15 \mathrm{~min}$. Plates were then rinsed with deionized water and the cells were fixed with $5 \%$ sodium thiosulfate for 3-5 min.

2.8. Immunohistochemistry. C3H10T1/2 cells were fixed with $10 \%$ neutral buffered formalin and washed with PBS. The fixed cells were then treated with $0.5 \%$ Nonidet P-40 for $10 \mathrm{~min}$ at room temperature for permeabilization and blocked with $10 \%$ serum for $30 \mathrm{~min}$ at $20^{\circ} \mathrm{C}$. The cells were then incubated with antibodies against collagen type I, osteocalcin, and osteopontin (all from Santa Cruz Biotechnology, Santa Cruz, CA, USA) at 1:1000 dilution for $1 \mathrm{~h}$. The cells were then washed and incubated with an appropriate biotinylated secondary antibody (1/4000) for $30 \mathrm{~min}$ followed by streptavidin-conjugated horseradish peroxidase for $20 \mathrm{~min}$ at 
room temperature. Proteins were counterstained with 3,30diaminobenzidine for visualization under the microscope. For the negative control, we used cells cultured for the same period of time in the absence of the synthetic peptides.

\section{Results and Discussion}

3.1. Structural Conservation of PfBMP-2. To examine the structural homology between Pinctada fucata, Drosophilidae family members, and vertebrate BMP-2, we performed a Dot matrix analysis [18] of the conserved amino acid sequences. As shown in Figure 1, PfBMP-2 has a high overall amino acid sequence homology with that of hBMP-2 and Xenopus BMP2 (Figures 1(a) and 1(d)), as well as that of the Drosophilidae homolog Dpp and Chordata Amphioxus BMP2/4 (Figures 1(c) and 1(e)). Human BMP-2 also has high homology with that of the Drosophilidae homolog Dpp and Chordata Amphioxus BMP2/4 (Figures 1(f) and $1(\mathrm{~g})$ ). The degree of homology is remarkable, even in the mature C-terminal portion of PfBMP-2 and the Drosophilidae homolog 60A (Figure 1(b)).

\subsection{Effect of the PfBMP-2 Mature Domain on the Differenti-} ation of $\mathrm{C} 3 \mathrm{H} 10 \mathrm{T1} / 2 \mathrm{Cells}$. To examine the osteogenic differentiative ability of PfBMP-2, we used the mouse C3H10T1/2 cell line, a murine embryonic mesenchymal cell line [20]. Previous reports showed that a synthetic peptide corresponding to residues 68-87 (NSVNSKIPKACCVPTELSAI) of the knuckle epitope of human BMP-2 could induce ectopic bone formation in vivo [21, 22], suggesting that this sequence is the functional domain of the mature human BMP-2. Another study identified that a peptide corresponding to amino acids 73-92 (KIPKASSVPTELSAISTLYL) of human BMP-2, which substituted Cys78, Cys79, and Met89 with Ser (S), Ser (S), and Thr (T), respectively, induced a higher alkaline phosphatase (ALP) activity than the original 6887 peptide [22]. This 73-92 peptide competes with rhBMP2 (recombinant human BMP-2) and can significantly inhibit the binding of rhBMP-2 to both receptors type IA and type II; this suggests that the substituted knuckle epitope has receptor binding capability [22]. Therefore, we used this substituted synthetic polypeptide as a positive control for the induction of osteogenesis.

We examined the functional conservation of the osteoinductive potential of PfBMP-2. Osteogenic differentiation in vitro was first confirmed using ALP activity. Figures 2(a) and 2(b) show the dose-response effects of recombinant PfBMP2 and the synthetic polypeptide of the knuckle epitope of human BMP-2 on ALP activity in C3H10T1/2 cells. ALP activity increased with increasing amounts of BMP-2 and reached a plateau at $2.5 \mu \mathrm{g}$ of $P f$ BMP-2 (Figure 2(a)) and $40 \mu \mathrm{g}$ of the synthetic BMP-2 (Figure 2(b)). Figure 3 shows the specific activity of ALP at various intervals after the addition of either control medium, recombinant $P f$ BMP-2, or the hBMP2 positive control polypeptide, respectively. ALP activity in $\mathrm{C} 3 \mathrm{H} 10 \mathrm{~T} 1 / 2$ cells treated with the recombinant $P f \mathrm{BMP}-2$ was significantly greater than that of the untreated cells versus $-\downarrow)$ and was twice that of the synthetic polypeptide of the knuckle epitope (- versus - $\mathbf{-}$ ) at about 7 days.
ALP and von Kossa staining methods are commonly used to indicate the presence of osteoblasts. Therefore, we examined the effects of BMP-2 on the osteogenic differentiation of $\mathrm{C} 3 \mathrm{H} 10 \mathrm{~T} 1 / 2$ cells using these histochemical techniques. As shown in Figure 4(a), ALP-positive cells were observed at 6 days in $\mathrm{C} 3 \mathrm{H} 10 \mathrm{~T} 1 / 2$ cells treated with the recombinant PfBMP-2 (1) and the hBMP-2 positive control (2), whereas there was negligible staining of the control C3H10T1/2 cells (3). We also examined the mineralized nodule formation in the cultures using von Kossa staining. As shown in Figure 4(b), mineralized nodule formation was observed at 6 days following the addition of either the recombinant PfBMP-2 (1) or hBMP-2 positive control polypeptide (2), as compared with the control cells (3). This mineralized matrix indicates the differentiation of $\mathrm{C} 3 \mathrm{H} 10 \mathrm{~T} 1 / 2$ stem cells into osteoblasts. Light microscopy showed that the undifferentiated C3H10T1/2 stem cells had a spindle-shaped fibroblastic phenotype (Figures 4(a) and 4(b) (3)), whereas the BMP-2treated cells had a cuboidal or elliptical morphology and had formed partial multilayers (Figures 4(a) and 4(b) $(1,2)$ ).

To determine the functional domain of $P f B M P-2$, a pairwise sequence alignment between $P f B M P-2$ and human BMP-2 was performed. As shown in Figure 5, the alignment depicts a high homology between these two mature proteins. The Pinctada fucata sequence contains almost the same residues of human BMP-2 (68-87) (NSVNSKIPKACCVPTELSAI). Therefore, we synthesized an additional polypeptide (PGSVPKPCCVPTELSSLSLL) containing the amino acid sequence of PfBMP-2 that showed the highest homology with the knuckle epitope of human BMP-2 and examined its osteogenic activity (herein referred to as PfBMP-2 synthetic polypeptide). Figure 6 shows the specific ALP activity observed at various intervals after the addition of the PfBMP2 synthetic polypeptide. Both the PfBMP-2 and hBMP-2 positive control synthetic polypeptides specifically increased ALP activity in C3H10T1/2 cells as compared with the

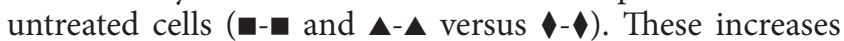
were approximately three times higher at 21 days in the treated cells over the control cells. We then used the ALP and von Kossa histological analyses as before. As shown in Figure 7(a), ALP-positive cells were observed at 21 days in C3H10T1/2 cells treated with the PfBMP-2 and hBMP-2 positive control synthetic polypeptides. In contrast, the staining for control C3H10T1/2 cells was negative. Furthermore, mineralized nodule formation was observed at 21 days for both synthetic polypeptides but not in the control cells (Figure $7(\mathrm{~b}))$.

3.3. Induction of Early and Late Osteogenic Markers in C3H10T1/2 Cells. The timing of the expression of each marker gene has been studied in detail in the differentiation process of stem cells. According to those reports, type I collagen is an early marker, alkaline phosphatase is an early/middle marker, and osteocalcin and osteopontin are late markers of bone formation $[23,24]$. In addition, the expression of osteopontin was somewhat earlier than that of osteocalcin in experiments using calvarial osteoblasts [23].

To further confirm the differentiation of C3H10T1/2 cells, the expression of early and late osteogenic marker genes 


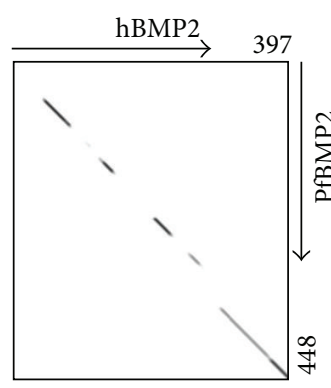

(a)

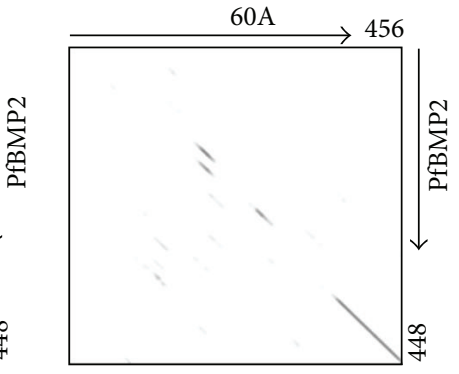

(b)

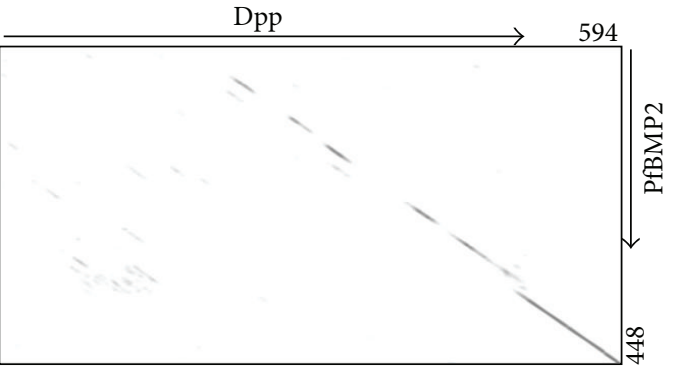

(c)

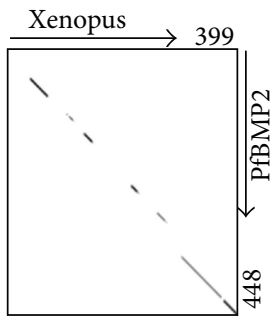

(d)

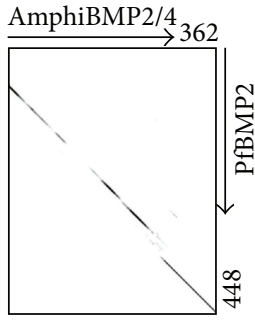

(e)

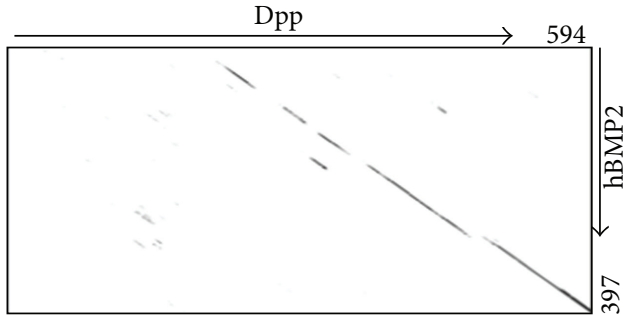

(f)

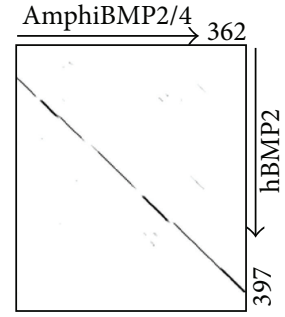

(g)

FIGURE 1: Dotlet comparison of $P f$ BMP-2 and other homologs. (a) Comparison of $P f$ BMP-2 with hBMP-2; (b) comparison of $P f$ BMP-2 with Drosophilidae 60A; (c) comparison of PfBMP-2 with Drosophilidae Dpp; (d) comparison of PfBMP-2 with Xenopus BMP-2; (e) comparison of PfBMP-2 with AmphiBMP2/4; (f) comparison of hBMP-2 with Drosophilidae Dpp; (g) comparison of hBMP-2 with AmphiBMP2/4. The total number of amino acids is shown numerically. The thin lined arrow indicates the direction of the amino acid sequence from the $\mathrm{N}$ - to the C-terminus. Abbreviations with GenBank accession number in parentheses; hBMP-2: human BMP-2 (NM001200); Pf BMP-2: Pinctada fucata BMP-2 (AB176952); Drosophilidae 60A: Drosophila transforming growth factor B-like protein (M77012); Dpp: Drosophila decapentaplegic protein (AF041439); Xenopus BMP-2: Xenopus laevis BMP-2 (NM001101666); AmphiBMP2/4: Branchiostoma floridae bone morphogenetic protein 2/4 (AF068750). Dotlet was performed at http://myhits.isb-sib.ch/cgi-bin/dotlet [17].

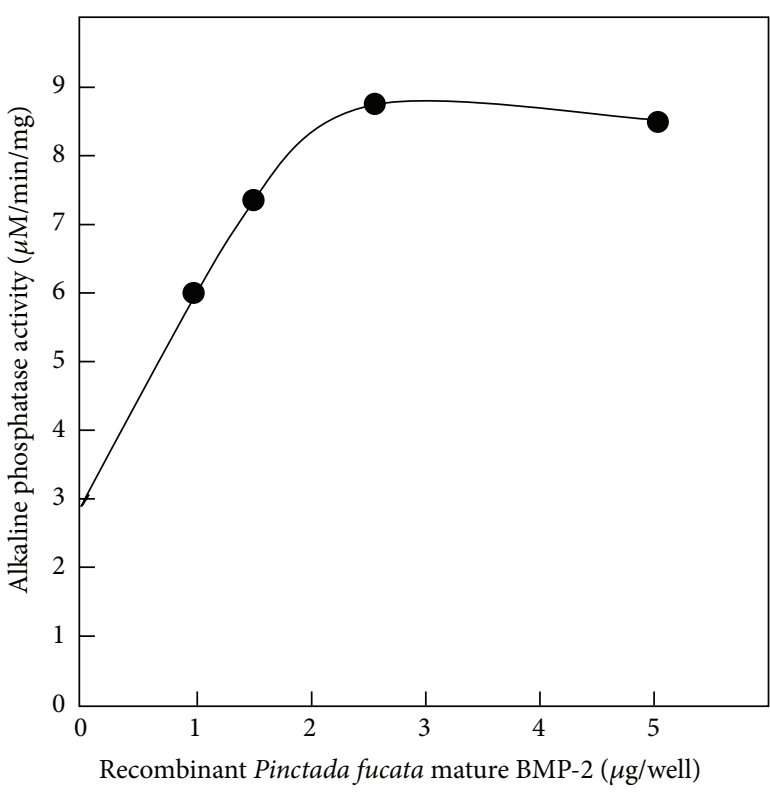

(a)

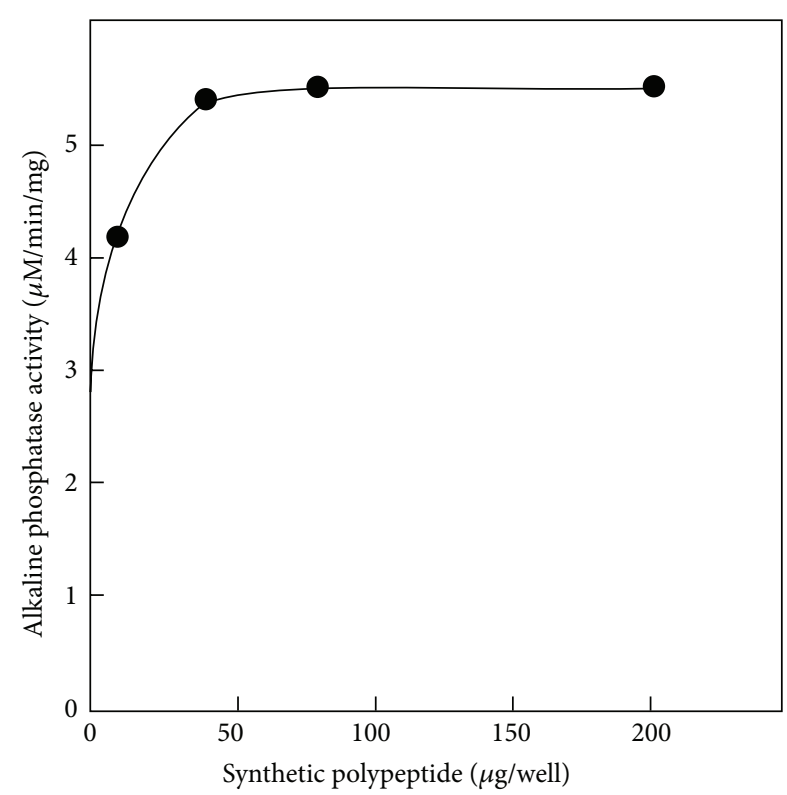

(b)

FIGURE 2: Dose-response effect of BMP-2 on alkaline phosphatase activity. C3H10T1/2 cells were plated into 48-well tissue culture dishes and cultured for 2 days under normal conditions. The cells were then cultured for a further 10 days with the recombinant mature domain of PfBMP-2 (a) (1.0, 1.5, 2.5, and $5 \mu \mathrm{g} /$ well) or the synthetic polypeptide of the knuckle epitope of human BMP-2 (b) (10, 40, 80, and 200 $\mu \mathrm{g} / \mathrm{well})$. The alkaline phosphatase in each well was then assayed and the results are presented as micromoles of p-nitrophenol (p-NP) produced per minute per milligram of protein. 


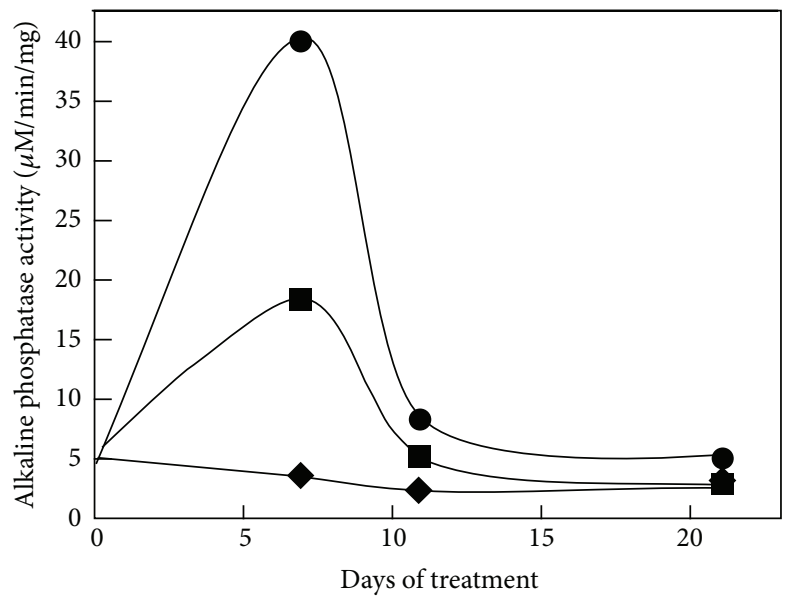

Figure 3: Effect of the recombinant mature domain of PfBMP-2 and the synthetic polypeptide of the knuckle epitope of human BMP-2 treatment on the endogenous expression of alkaline phosphatase in C3H10T1/2 cells. C3H10T1/2 cells were plated into 48-well tissue culture dishes for 2 days followed by incubation with the recombinant mature BMP-2 and the synthetic polypeptide of the Knuckle epitope of human BMP-2 at a final concentration of $5 \mu \mathrm{g} /$ well and $80 \mu \mathrm{g} / \mathrm{well}$, respectively. At 7, 11, and 21 days, alkaline phosphatase expression was measured, as indicated. - Pf BMP-2; $\square$ : the Knuckle epitope of human BMP-2 synthetic polypeptide;
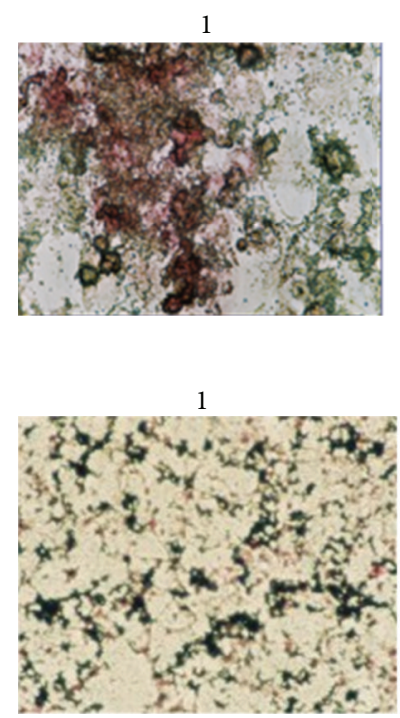

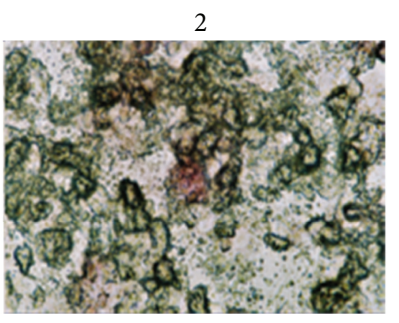

(a)

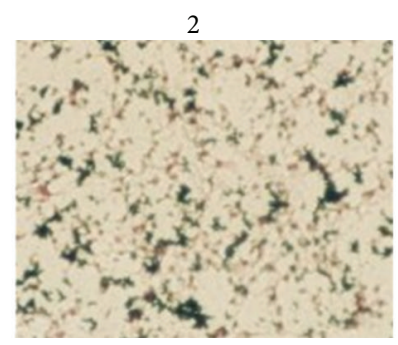

(b)

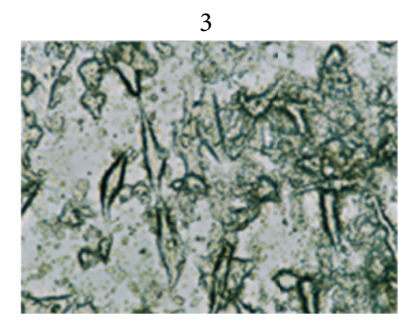

3

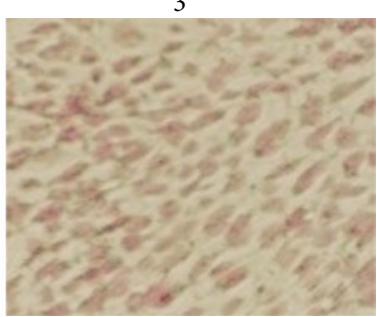

Figure 4: Histochemical analysis. C3H10T1/2 cells were plated into $40 \mathrm{~mm}$ culture dishes and cultivated for 2 days. Cells were then treated with $250 \mathrm{ng} / \mathrm{mL}$ recombinant mature BMP-2 or $1 \mu \mathrm{g} / \mathrm{mL}$ synthetic polypeptide of the knuckle epitope of human BMP-2 for 6 days culture before staining. (a) Alkaline phosphatase staining at 6 days. (b) von Kossa staining at 6 days. 1: recombinant PfBMP-2; 2: the synthetic polypeptide of the knuckle epitope of human BMP-2; and 3: control culture. Cells were photographed at 100x magnification.

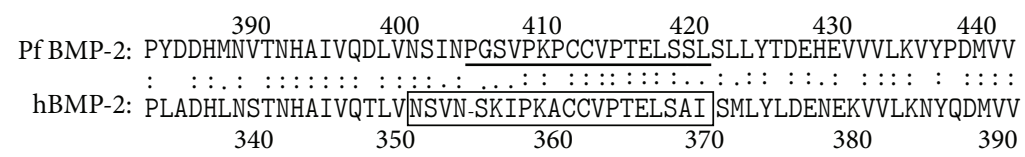

FIGURE 5: Pairwise sequence alignment of PfBMP-2 and human BMP-2. The residue numbers indicate the positions of the amino acids in the BMP-2 precursor before processing. The closed box indicates the human BMP-2 functional domain (the knuckle epitope of human BMP-2). The bold underline indicates the synthetic polypeptides for examining the osteogenic activity of PfBMP-2. : denotes identical residues in two BMP-2 orthologs; • denotes a moderately conserved residue. 


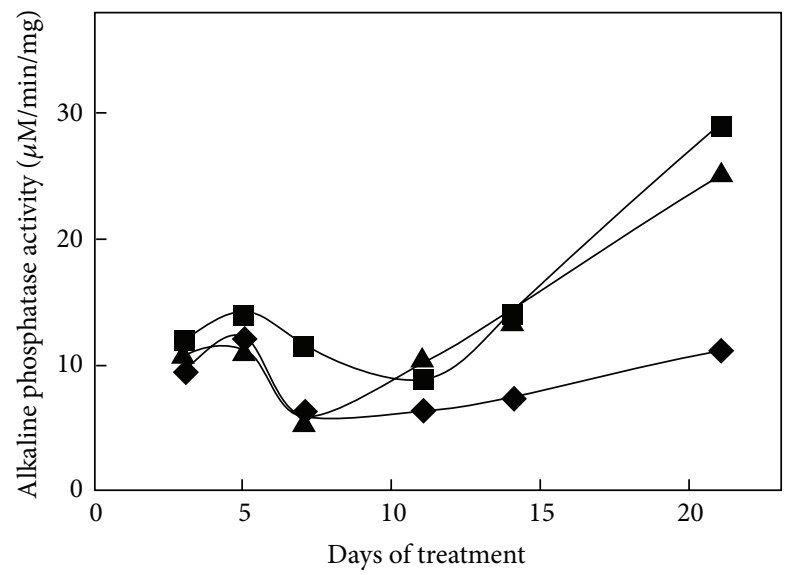

Figure 6: Effects of the PfBMP-2 synthetic polypeptide and the synthetic polypeptide of the knuckle epitope of human BMP-2 on the endogenous expression of alkaline phosphatase in C3H10T1/2 cells. C3H10 T1/2 cells were plated into 48-well dishes for 2 days and then treated with $80 \mu \mathrm{g} /$ well $\mathrm{Pf}$ BMP-2 synthetic polypeptide or $80 \mu \mathrm{g} /$ well synthetic polypeptide of the knuckle epitope of human BMP-2. Alkaline phosphatase activity was measured at endpoint, on the days indicated. $\mathbf{\square}-\mathbf{\square}$ : the knuckle epitope of human BMP-2, $\mathbf{\Delta - \Delta}$ : Pf BMP-2 synthetic polypeptide, and - in the absence of protein.
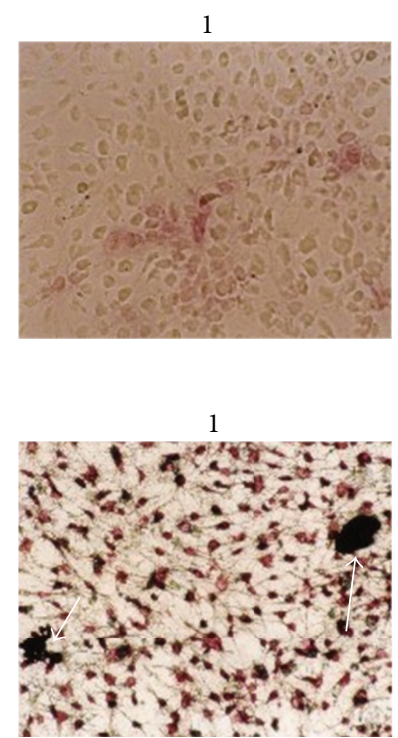

2

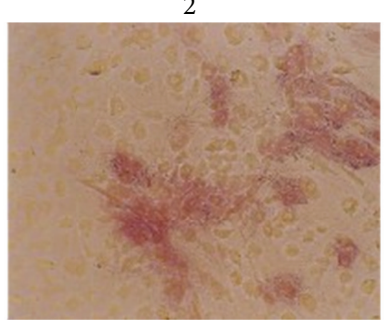

(a)

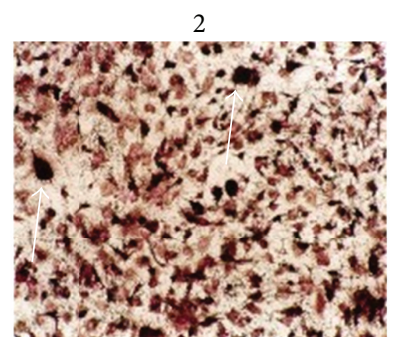

(b)

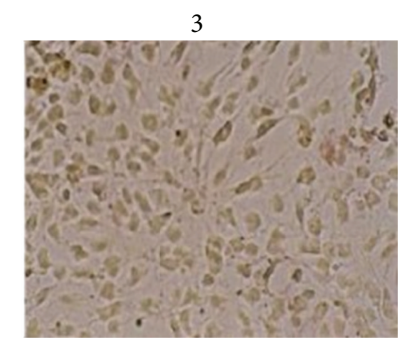

3

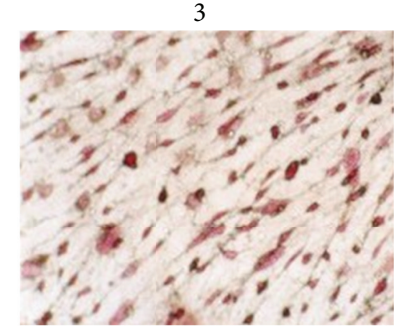

FIGURE 7: Histochemical analysis. C3H10T1/2 cells were plated into $40 \mathrm{~mm}$ culture dishes for 2 days. Cells were then treated with $250 \mathrm{ng} / \mathrm{mL}$ Pf BMP-2 synthetic polypeptide or $1 \mu \mathrm{g} / \mathrm{mL}$ synthetic polypeptide of the knuckle epitope of human BMP-2 for the indicated time periods. (a) Staining for alkaline phosphatase was performed after 21 days. (b) von Kossa staining at 21 days. 1: the PfBMP-2 synthetic polypeptide; 2 : the synthetic polypeptide of the knuckle epitope of human BMP-2; 3: control culture. The white arrows indicate the areas of calcification. Cells were photographed at 100x magnification.

(collagen type I, osteopontin, and osteocalcin) was examined in C3H10T1/2 cells treated with the PfBMP-2 or hBMP-2 positive control synthetic polypeptides. Cells were fixed after 7-18 days in culture and were subjected to immunohistochemical staining for collagen type I, osteopontin, and osteocalcin. The expression of collagen type I after 7 days in culture (Figure 8(a)), osteopontin after 13 days in culture (Figure 8(b)), and osteocalcin after 18 days in culture (Figure $8(\mathrm{c})$ ) was detected in the $\mathrm{C} 3 \mathrm{H} 10 \mathrm{~T} 1 / 2$ cells treated with both polypeptides. These results confirm the conserved osteogenic inductive function of BMP-2 across invertebrates and vertebrates.
3.4. Signaling Pathways and PfBMP-2 Activity: Future Directions. The PfBMP-2 and hBMP-2 positive control synthetic polypeptides may interact with the type II receptor of BMP2 . The signal transduction pathways involved in BMP-2mediated osteogenesis have been well studied. The binding of TGF- $\beta / \mathrm{BMP}-2$ to type I and type II serine/threonine kinase heterotetrameric receptor complexes leads to the activation of the SMAD-dependent canonical pathway and the SMADindependent noncanonical pathways including PI3K/Akt, ERK (extracellular signal-regulated kinase), JNK (c-jun Nterminal kinase), and p38 $[25,26]$. In the SMAD-dependent 

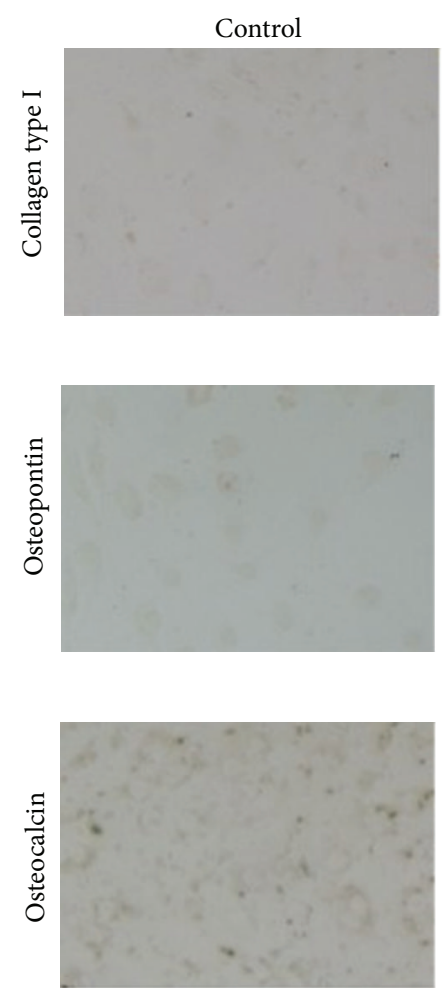

Pf BMP-2

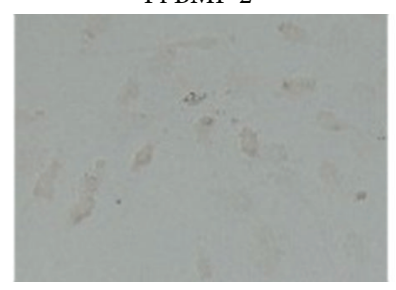

(a)

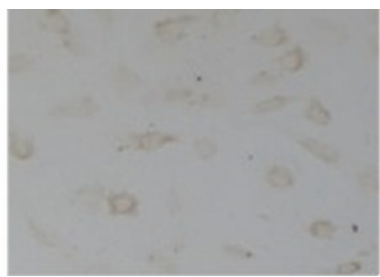

(b)

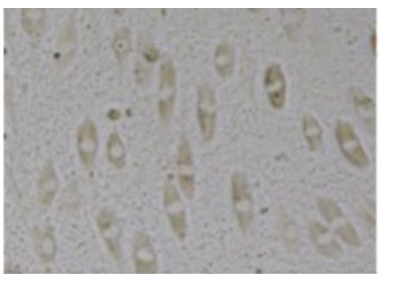

(c)
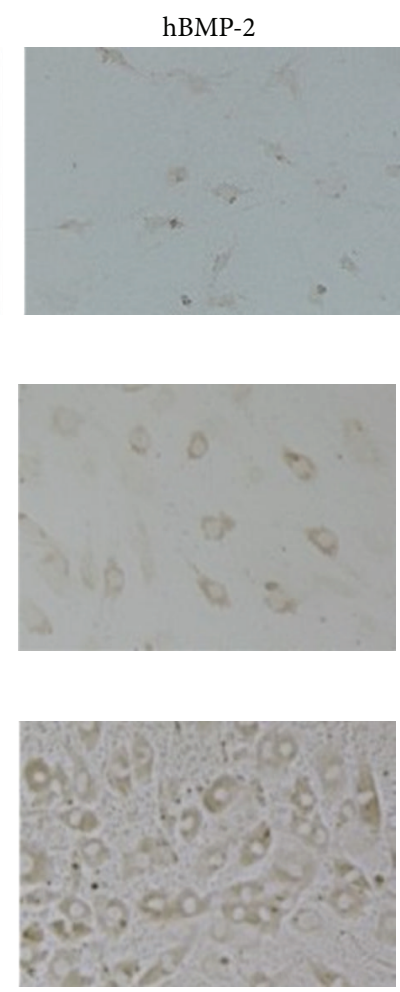

FIGURE 8: Immunohistochemical staining for osteogenic markers in C3H10T1/2 cells. C3H10T1/2 cells were plated into 40 mm culture dishes for 2 days and then treated with $250 \mathrm{ng} / \mathrm{mL}$ PfBMP-2 synthetic polypeptide or $1 \mu \mathrm{g} / \mathrm{mL}$ synthetic polypeptide of the knuckle epitope of human BMP-2 (hBMP-2) for the indicated time periods. (a) Immunohistochemical staining of collagen type I after 7 days in culture. (b) Immunohistochemical staining of osteopontin after 13 days in culture. (c) Immunohistochemical staining of osteocalcin after 18 days in culture. Cells were photographed at 100x magnification.

canonical pathway, Runx2 transcription is induced by transcription factors, such as Smad4 and Smad1/5. Runx2 associated with Smad1/5 induces the transcription of target genes involved in bone formation $[25,26]$. In the SMADindependent noncanonical pathways, BMP signaling induces the expression of Dlx5. After that, phosphorylated Dlx5 induces the expression of Runx2 [27, 28]. Finally, these two pathways converge on Runx2 expression. Runx 2 induces the expression of osteogenic marker genes, such as collagen type I, BSP, osteocalcin, and osteopontin [29].

However, it remains unclear whether these canonical and noncanonical pathways also mediate the activity of PfBMP-2 in the nacreous or the prismatic layer formation. Many genes participate in the nacreous or prismatic layer formation, such as the nacrein [30], N16/Pearlin [31, 32], N19 [33], Pif [34], and prismalin 14 [35]. While it has been reported that c-jun activates nacrein transcription via the AP-1 site located in the 5 flanking region [36], there are very few other reports in this field. Thus, studying the regulation of genes involved in hard tissue formation of mollusk shells is an important future subject.

Previous reports showed that the mature region of recombinant human BMP-2 [37] and the recombinant Drosophila Dpp and A60 homolog can induce bone formation [17] without posttranslational modifications such as glycosylation, phosphorylation, acetylation, sumoylation, or other types of modification. However, with the exception of BMP-3, BMPs are glycosylated on a conserved $\mathrm{N}$-glycosylation sequence (NXS/T) in the mature protein domain [38-40], which is important for its function. Indeed, the biological activity of BMP-2 and BMP-7 was reduced following chemical deglycosylation [41], and N-glycosylation at the Asn 73 residue in the wrist epitope of BMP- 6 is essential for its recognition by the type I receptor [42]. PfBMP-2 retains this NXS/T sequence. We performed a prediction of the $\mathrm{N}$-glycosylation site of PfBMP-2 and found two potential N-glycosylation sites at Asn 37 or Asn 97 or both (data not shown). We believe that Nglycosylation at these site(s) may contribute to the function of PfBMP-2, and this will also be the focus of future studies.

\section{Conclusion}

BMP-2 induces mesenchymal cell differentiation into osteoblasts in vitro. We examined the functional interchangeability of Pinctada fucata and human BMP-2 synthetic peptides on the osteogenic differentiation of C3H10T1/2 murine mesenchymal stem cell cultures. Exposure of the C3H10T1/2 cells to the recombinant mature fragment of PfBMP-2 resulted in osteogenic differentiation. The equivalent sequence from the knuckle epitope of human BMP-2 also 
induced osteogenic differentiation of C3H10T1/2 cells. Osteogenic induction was confirmed by an increase in ALP activity, the accumulation of calcium, and the protein expression of osteogenic markers. These results show that BMP-2 is conserved not only in terms of homology, but also in terms of its function in the formation of hard tissue.

\section{References}

[1] R. Derynck and K. Miyazono, "TGF-beta and the TGF-beta family," in The TGF-Beta Family, R. Derynck and K. Miyazono, Eds., pp. 29-43, Cold Spring Harbor Laboratory Press, New York, NY, USA, 2008.

[2] R. Derynck and R. J. Akhurst, "Differentiation plasticity regulated by TGF- $\beta$ family proteins in development and disease," Nature Cell Biology, vol. 9, no. 9, pp. 1000-1004, 2007.

[3] Q. Li, J. E. Agno, M. A. Edson, A. K. Nagaraja, T. Nagashima, and M. M. Matzuk, "Transforming growth factor $\beta$ receptor type 1 is essential for female reproductive tract integrity and function," PLoS Genetics, vol. 7, Article ID e1002320, 2011.

[4] A. J. Nederbragt, A. E. van Loon, and W. J. A. G. Dictus, "Expression of Patella vulgata orthologs of engrailed and dpp-BMP2/4 in adjacent domains during molluscan shell development suggests a conserved compartment boundary mechanism," Developmental Biology, vol. 246, no. 2, pp. 341-355, 2002.

[5] M. Iijima, T. Takeuchi, I. Sarashina, and K. Endo, "Expression patterns of engrailed and dpp in the gastropod Lymnaea stagnalis," Development Genes and Evolution, vol. 218, no. 5, pp. 237251, 2008.

[6] C. Lelong, M. Mathieu, and P. Favrel, "Structure and expression of mGDF, a new member of the transforming growth factor- $\beta$ supwrfamily in the bivalve mollusc Crassostrea gigas," European Journal of Biochemistry, vol. 267, no. 13, pp. 3986-3993, 2000.

[7] A. Herpin, C. Lelong, T. Becker, F. Rosa, P. Favrel, and C. Cunningham, "Structural and functional evidence for a singular repertoire of BMP receptor signal transducing proteins in the lophotrochozoan Crassostrea gigas suggests a shared ancestral BMP/activin pathway," FEBS Journal, vol. 272, no. 13, pp. 34243440, 2005.

[8] T. Miyashita, T. Hanashita, M. Toriyama, R. Takagi, T. Akashika, and N. Higashikubo, "Gene cloning and biochemical characterization of the BMP-2 of Pinctada fucata," Bioscience, Biotechnology and Biochemistry, vol. 72, no. 1, pp. 37-47, 2008.

[9] C. Li, Y. Hu, J. Liang et al., "Calcineurin plays an important role in the shell formation of pearl oyster (Pinctada fucata)," Marine Biotechnology, vol. 12, no. 1, pp. 100-110, 2010.

[10] L. M. Helvering, R. L. Sharp, X. Ou, and A. G. Geiser, "Regulation of the promoters for the human bone morphogenetic protein 2 and 4 genes," Gene, vol. 256, no. 1-2, pp. 123-138, 2000.

[11] M. Tomita, M. I. Reinhold, J. D. Molkentin, and M. C. Naski, "Calcineurin and NFAT4 induce chondrogenesis," Journal of Biological Chemistry, vol. 277, no. 44, pp. 42214-42218, 2002.

[12] E. Lopez, B. Vidal, S. Berland, S. Camprasse, G. Camprasse, and C. Silve, "Demonstration of the capacity of nacre to induce bone formation by human osteoblasts maintained in vitro," Tissue and Cell, vol. 24, no. 5, pp. 667-679, 1992.

[13] C. Silve, E. Lopez, B. Vidal et al., "Nacre initiates biomineralization by human osteoblasts maintained in vitro," Calcified Tissue International, vol. 51, no. 5, pp. 363-369, 1992.

[14] M. Lamghari, M. J. Almeida, S. Berland et al., "Stimulation of bone marrow cells and bone formation by nacre: in vivo and in vitro studies," Bone, vol. 25, no. 1, pp. 91S-94S, 1999.
[15] H. Liao, H. Mutvei, L. Hammarström, T. Wurtz, and J. Li, "Tissue responses to nacreous implants in rat femur: an in situ hybridization and histochemical study," Biomaterials, vol. 23, no. 13, pp. 2693-2701, 2002.

[16] P. Westbroek and F. Marin, "A marriage of bone and nacre," Nature, vol. 392, no. 6679, pp. 861-862, 1998.

[17] T. K. Sampath, K. E. Rashka, J. S. Doctor, R. F. Tucker, and F. M. Hoffmann, "Drosophila transforming growth factor $\beta$ superfamily proteins induce endochondral bone formation in mammals," Proceedings of the National Academy of Sciences of the United States of America, vol. 90, no. 13, pp. 6004-6008, 1993.

[18] M. Pagni and T. Junier, "Dotlet: powerful and easy strategy for pairwise comparisons," Journal of Cell and Molecular Biology, vol. 7-8, no. 1-2, pp. 81-82, 2010.

[19] T. Miyashita, K. Hirotaka, and R. Takagi, "Expression and purification of the recombinant mature bone morphogenetic protein-2 of Pinctada fucata in Escherichia coli and comparison of the codon usage," Memoirs of the School of Biology-Oriented Science and Technology of Kinki University, no. 18, pp. 1-7, 2006.

[20] C. A. Reznikoff, D. W. Brankow, and C. Heidelberger, "Establishment and characterization of a cloned line of $\mathrm{C} 3 \mathrm{H}$ mouse embryo cells sensitive to postconfluence inhibition of division," Cancer Research, vol. 33, no. 12, pp. 3231-3238, 1973.

[21] Y. Suzuki, M. Tanihara, K. Suzuki, A. Saitou, and Y. Nishimura, "Alginate hydrogel linked with synthetic oligopeptide derived from BMP-2 allows ectopic osteoinduction in vivo," Journal of Biomedical Materials Research, vol. 50, pp. 405-409, 2000.

[22] A. Saito, Y. Suzuki, S. I. Ogata, C. Ohtsuki, and M. Tanihara, "Activation of osteo-progenitor cells by a novel synthetic peptide derived from the bone morphogenetic protein-2 knuckle epitope," Biochimica et Biophysica Acta, vol. 1651, no. 1-2, pp. 6067, 2003.

[23] R. T. Franceschi, "The developmental control of osteoblastspecific gene expression: role of specific transcription factors and the extracellular matrix environment," Critical Reviews in Oral Biology and Medicine, vol. 10, no. 1, pp. 40-57, 1999.

[24] J. Frith and P. Genever, "Transcriptional control of mesenchymal stem cell differentiation," Transfusion Medicine and Hemotherapy, vol. 35, no. 3, pp. 216-227, 2008.

[25] R. Nishimura, K. Hata, T. Matsubara, M. Wakabayashi, and T. Yoneda, "Regulation of bone and cartilage development by network between BMP signalling and transcription factors," The Journal of Biochemistry, vol. 151, pp. 247-254, 2012.

[26] G. Chen, C. Deng, and Y. P. Li, "TGF- $\beta$ and BMP signaling in osteoblast differentiation and bone formation," International Journal of Biological Sciences, vol. 8, no. 2, pp. 272-288, 2012.

[27] A. Ulsamer, M. J. Ortuño, S. Ruiz et al., "BMP-2 induces Osterix expression through up-regulation of Dlx 5 and its phosphorylation by p38," Journal of Biological Chemistry, vol. 283, no. 7, pp. 3816-3826, 2008.

[28] M. H. Lee, Y. J. Kim, W. J. Yoon et al., "Dlx5 specifically regulates Runx2 type II expression by binding to homeodomain-response elements in the Runx2 distal promoter," Journal of Biological Chemistry, vol. 280, no. 42, pp. 35579-35587, 2005.

[29] T. Komori, "Regulation of osteoblast differentiation by Runx2," Advances in Experimental Medicine and Biology, vol. 658, pp. 43-49, 2010.

[30] H. Miyamoto, T. Miyashita, M. Okushima, S. Nakano, T. Morita, and A. Matsushiro, "A carbonic anhydrase from the nacreous layer in oyster pearls," Proceedings of the National Academy of Sciences of the United States of America, vol. 93, no. 18, pp. 96579660, 1996. 
[31] T. Samata, N. Hayashi, M. Kono, K. Hasegawa, C. Horita, and S. Akera, "A new matrix protein family related to the nacreous layer formation of Pinctada fucata," FEBS Letters, vol. 462, no. 1-2, pp. 225-229, 1999.

[32] T. Miyashita, R. Takagi, M. Okushima et al., "Complementary DNA cloning and characterization of Pearlin, a new class of matrix protein in the nacreous layer of oyster pearls," Marine Biotechnology, vol. 2, no. 5, pp. 409-418, 2000.

[33] M. Yano, K. Nagai, K. Morimoto, and H. Miyamoto, "A novel nacre protein N19 in the pearl oyster Pinctada fucata," Biochemical and Biophysical Research Communications, vol.362, pp. 158163, 2007.

[34] M. Suzuki, K. Saruwatari, T. Kogure et al., "An acidic matrix protein, Pif, is a key macromolecule for nacre formation," Science, vol. 325, no. 5946, pp. 1388-1390, 2009.

[35] M. Suzuki, E. Murayama, H. Inoue et al., "Characterization of Prismalin-14, a novel matrix protein from the prismatic layer of the Japanese pearl oyster (Pinctada fucata)," Biochemical Journal, vol. 382, no. 1, pp. 205-213, 2004.

[36] T. Miyashita, A. Takami, and R. Takagi, "Molecular cloning and characterization of the $5^{\prime}$-flanking regulatory region of the carbonic anhydrase nacrein gene of the pearl oyster Pinctada fucata and its expression," Biochemical Genetics, vol. 50, no. 9-10, pp. 673-683, 2012.

[37] E. A. Wang, V. Rosen, J. S. D’Alessandro et al., "Recombinant human bone morphogenetic protein induces bone formation," Proceedings of the National Academy of Sciences of the United States of America, vol. 87, no. 6, pp. 2220-2224, 1990.

[38] C. C. Rider and B. Mulloy, "Bone morphogenetic protein and growth differentiation factor cytokine families and their protein antagonists," Biochemical Journal, vol. 429, no. 1, pp. 1-12, 2010.

[39] E. Ozkaynak, P. N. J. Schnegelsberg, D. F. Jin et al., "Osteogenic protein-2. A new member of the transforming growth factor$\beta$ superfamily expressed early in embryogenesis," Journal of Biological Chemistry, vol. 267, no. 35, pp. 25220-25227, 1992.

[40] J. Groppe, K. Rumpel, A. N. Economides, N. Stahl, W. Sebald, and M. Affolter, "Biochemical and biophysical characterization of refolded Drosophila DPP, a homolog of bone morphogenetic proteins 2 and 4," Journal of Biological Chemistry, vol. 273, no. 44, pp. 29052-29065, 1998.

[41] J.-J. A. Zhou, Enhancing production of recombinant BMP-2 in mammalian cell culture systems by inhibition of pro-protein cleavage using 9DR peptides [M.S. thesis], University of Toronto, 2008.

[42] S. Saremba, J. Nickel, A. Seher, A. Kotzsch, W. Sebald, and T. D. Mueller, "Type I receptor binding of bone morphogenetic protein 6 is dependent on $\mathrm{N}$-glycosylation of the ligand," FEBS Journal, vol. 275, no. 1, pp. 172-183, 2008. 

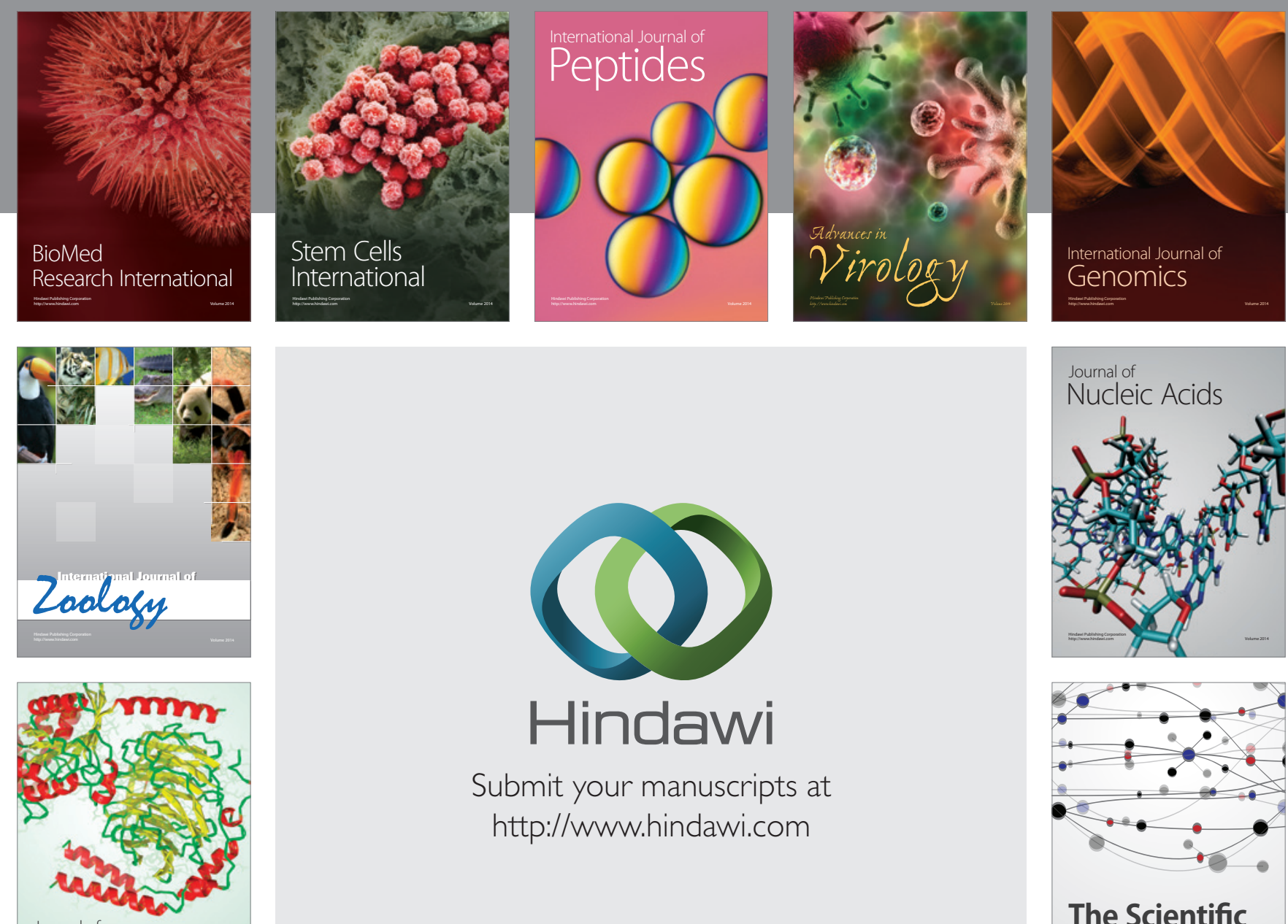

Submit your manuscripts at

http://www.hindawi.com

Journal of
Signal Transduction
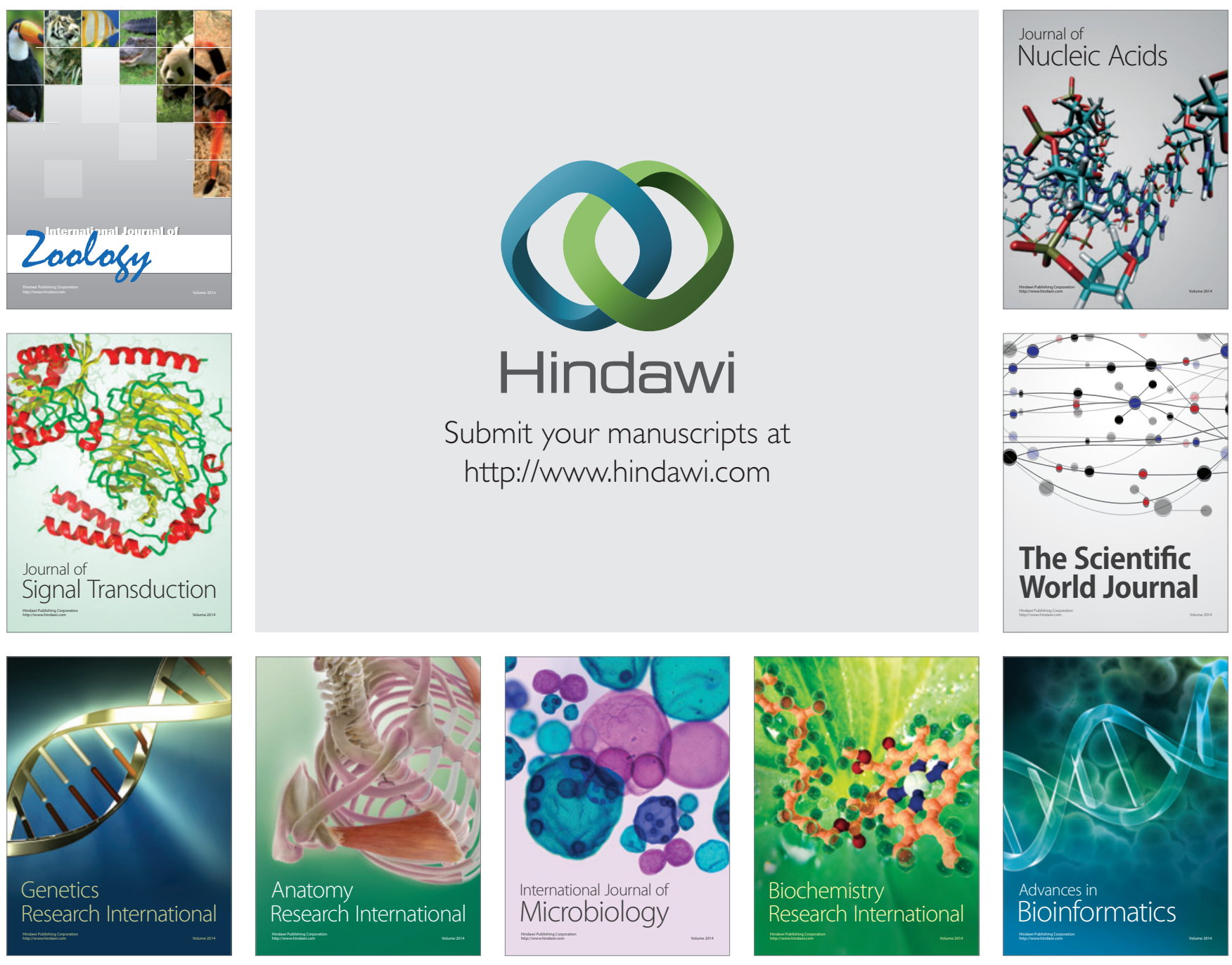

The Scientific World Journal
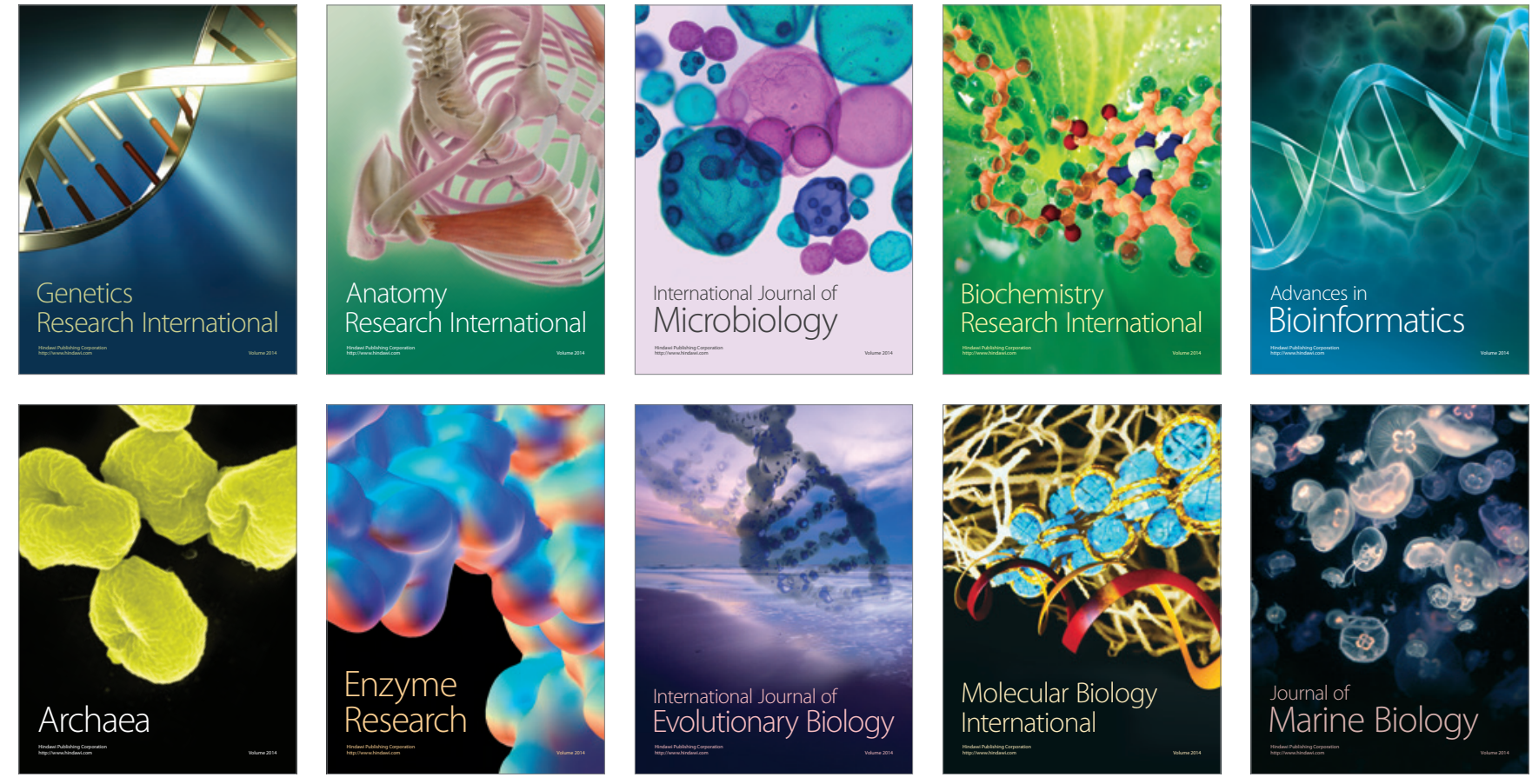